\title{
Anomalous origin of single coronary artery with multiple heart malformations
}

Sir:

It is a pity that this interesting report by Zachariah and Reif (1974, 36, II44) perpetuates the myth of the single coronary artery arising from the innominate artery. I believe that the vessel concerned is in fact the hypoplastic ascending aorta, a component of the hypoplastic left heart of mitral and/or aortic valve atresia - possibly the commonest cause of congenital cardiovascular death in the stillborn or neonate. The authors' 'truncus type III' is really the pulmonary trunk continuing into the wide ductus arteriosus; naturally, the vessel has no coronary ostia and it joins the aortic arch distally. Microdissection might demonstrate coronary ostia in the root of the tiny ascending aorta.

The matter is referred to in my monograph (Hudson, 1965).

Reginald E. B. Hudson 'Thalassa', West Beach Road, Shoreham-by-Sea, Sussex, BN4 5LF.

\section{Reference}

Hudson, R. E. B. (1965). Cardiovascular Pathology, pp. 2057-58. Edward Arnold, London.

Sir :

We believe that the case reported by Zachariah and Reif is not really a single coronary artery.

Probably, what the authors think to be a coronary artery is an ascending hypoplastic aorta with an atretic valve. In our opinion, this is a case of mitral atresia with hypoplastic left ventricle, aortic atresia, and hypoplastic ascending aorta.

The pulmonary artery looks like a truncus because it drains into the descending aorta through the ductus.

\section{Dr. Alberto Cabrera, Dr. Ignacio Azcuna, Hospital Infantil, Bilbao, Spain.}

These letters were shown to Dr. Reif who comments as follows.

Sir:

We agree that the possibility exists that the 'single coronary artery' is really a hypoplastic aorta which gives rise to two coronary arteries of relatively large size. Furthermore, we believe that the case published by Keeling (1970) represents the same malformation of a hypoplastic aorta.

$$
\begin{aligned}
& \text { R. Reif, } \\
& \text { Department of Pathology, } \\
& \text { 'Asaf Harofe' Government } \\
& \text { Hospital, } \\
& \text { Zerifin, } \\
& \text { Israel. }
\end{aligned}
$$

\section{Reference}

Keeling, J. W. (1970). Anomalous origin of a single coronary artery. Fournal of Pathology, 102, 174. 